\title{
Más sobre la recepción literaria
}

FRANCO MEREGALLI

Universidad de Venecia

En 1979 redacté un escrito que se publicó en 1980 en la Revue de littérature comparée bajo el título «Sur la réception littéraire»; más tarde pensé en una elaboración del mismo, en que se introducían algunos elementos nuevos, dirigida a un público hispánico, y con referencias específicas a textos hispánicos: se trata de las páginas que siguen.

Desde la Antigüedad, y hasta el siglo XVIII, la civilización europea estudió el hecho literario sobre todo como texto. Sólo el romanticismo puso de relieve más bien al autor, individual o colectivo; al autor atribuye el genio, la originalidad. El positivismo, que reacciona contra determinados aspectos del romanticismo, pero continúa otros, estudia con predilección el hecho circunstancial, el hombre y sus tiempos. El positivismo ha tenido muchas manifestaciones, y parece injusto acusarlo de sus defectos sin poner de relieve sus méritos. Pero se comprende que contra él haya habido distintas reacciones. En Italia el neoidealismo reaccionó contra el culto del dato erudito como fin en sí mismo; pero continuó también, en cierto sentido, como el positivismo, el romanticismo, con su rechazo de la retórica y del análisis detenido del texto. Otra forma de reacción contra el positivismo, al contrario, se manifestó en una vuelta al texto, que encontramos en movimientos diferentes, como el formalismo ruso, el New criticism norteamericano, la Textimmanenz 
alemana y por fin el estructuralismo francés. Se llegó a una recuperación de la retórica (por ejemplo en la escuela de Chicago) y a un culto ahistórico del texto. La influencia de la lingüística general (Jakobson) se ejerció en esta dirección, como es natural, puesto que el lingüista se ocupa naturalmente de textos y no de realidades extratextuales como la vida del autor, su personalidad, sus condicionamientos históricos. Se llegó hasta negar la historia literaria.

Sin embargo, ya en el formalismo ruso se afirma la historicidad de la obra literaria, aunque limitando esta historicidad al ámbito literario.

Esta tendencia al estudio autónomo del texto fue tan fuerte que ni siquiera la presencia vigorosa del marxismo, y más en general del interés por los fenómenos sociales, consiguió contrastarla. Pero la negación de la historicidad del hecho literario choca contra la evidencia de los hechos, de manera que ni siquiera en los años sesenta, los de la máxima vigencia del culto ahistórico del texto, la historia literaria fue abandonada. A la larga las exigencias que triunfan revelan su unilateralidad, y se manifiestan reacciones que quieren satisfacer nuevas exigencias. De todas formas, la investigación literaria del pasado, lo mismo la que ponía el acento en el texto que la que se ocupaba preferentemente del autor y de su tiempo, limitaba su atención a la producción y al producto de la literatura. En realidad, esta producción no puede entenderse sino en una relación dialéctica con el destinatario. El destinatario determina ampliamente el carácter de la actividad del autor y el carácter de la obra; y por lo demás el autor ha sido un destinatario, se coloca en una cadena, que se puede llamar género literario u otra cosa, pero que de todas formas es esencial para comprender el mismo texto individual. No existe el texto sin el contexto. La lectura ahistórica y atópica de un texto es una ilusión. Ya la interpretación literal de cualquier texto sería imposible sin su colocación histórica, porque las palabras cambian de significado con el cambio del tiempo: la lengua es intrínsecamente historia. Y el contexto implica la presencia del receptor como elemento motivador de la actividad literaria.

En esta perspectiva histórica se explica la afirmación reciente de un movimiento que desplaza la atención hacia el aspecto de la vida literaria que más se descuidó en el pasado: el receptor. Este movimiento se afirmó sobre todo en Alemania, y no casualmente: se trata de la $R e$ zeptionsästhetik de la llamada escuela de Constanza, representada por Jauss e Iser particularmente. Estos autores no afirman sus teorías como si fueran algo completamente nuevo. Al contrario, citan como an- 
tecedentes a Ingarden, a Mukarovsky, a Gadamer, etc. Estos autores habían desarrollado el concepto de concreción de la obra literaria, que es central en la teoría de la recepción literaria. En realidad, cada receptor de una obra la recibe a su manera, hace una elección de los elementos que encuentra en ella según sus preferencias más o menos conscientes; reconstruye el texto prestándole elementos de su experiencia. El texto, desde luego, es único e invariable; pero cada uno lo experimenta a su manera. Iser distinguió entre texto y obra, entendiendo por obra el texto en la concreción hecha por cada uno.

La vieja historia literaria estaba hecha desde el punto de vista del emisor; este punto de vista, en efecto, tiene una importancia determinante. Pero el punto de vista del receptor es también importante y debe ser relacionado dialécticamente con el otro. Nótese este hecho: Jauss, acusado de afirmar con exclusivismo la importancia del punto de vista del receptor, precisó que sus afirmaciones no debían interpretarse como alternativas a las prácticas tradicionales de la historia literaria, sino como integrativas. Y en efecto, se puede observar que a menudo afirmaciones que se hacen contraponiéndolas a otras son en realidad no contrarias a éstas, sino complementarias de éstas; y se consideran contrarias sólo en función de la situación existencial del que las hace. Es un procedimiento natural el de afirmarse contraponiéndose; pero a menudo la oposición tiene tan sólo un carácter anecdótico.

Se preguntará uno por qué estas afirmaciones de Jauss, junto con las consideraciones de otros, por ejemplo las de Iser sobre el fenómeno de la lectura, van bajo el nombre de estética de la recepción. En efecto, yo encuentro que esta denominación puede llevar a interpretaciones inexactas y a veces contrarias a las mismas intenciones de los afirmadores de la Rezeptionsästhetik. Jauss e Iser se ocupan en realidad de literatura. Pero es evidente que la actividad estética comprende también otras manifestaciones, como la música o las artes espaciales. Es más. El término estética parece aplicarse más característicamente a la música o a las artes espaciales que a la literatura. No es éste el lugar para discutir ampliamente sobre qué es literatura ${ }^{1}$. En realidad, afirmó recientemente Todorov, este término resulta de significación muy borrosa, hasta

1 He publicado un escrito sobre What is literature? en el homenaje a Horst Rüdiger: Wege zur Komparatistik («Sonderheft» de Arcadia, 1983, 71-80). Mientras tanto, el amigo Rüdiger ha fallecido, nov. 1984. Permítaseme que a su memoria dedique este escrito. 
el punto que Todorov prefiere sustituir a la tradicional expresión géneros literarios la otra de genres du discours. De todas formas, aun aceptando la utilidad del término literatura, parece evidente que la literatura está caracterizada por su polisemicidad. El mismo Mukarovski afirmaba que los elementos extraestéticos son esenciales en ella. La literatura se expresa con medios lingüísticos, y la lengua puede reflejar todas las experiencias de la humanidad: no sólo la experiencia de las sensaciones, de las emociones, lo que se dice experiencia estética, sino también la reflexión sobre el destino humano, la angustia religiosa, la toma de conciencia ética, el juego intelectual. La música tiene un coeficiente estético más evidente que la literatura; pero no tiene el carácter de totalidad que tiene la literatura. Podríamos enunciar esta diferencia afirmando que la literatura tiene un carácter holístico, mientras la música tiene un carácter predominantemente estético. Nuestra educación literaria, consciente o inconscientemente derivada de preferencias simbolistas, tiende a considerar predominante, desde el punto de vista del valor, el elemento estético. El mismo Mukarovsky, al contraponer en la obra literaria lo estético y lo extraestético, afirmaba este predominio de lo estético en la literatura indicando los elementos no estéticos de la obra literaria sólo con la calificación negativa (extraestético). Pero la grandeza de la literatura está precisamente en la posibilidad de expresar todo lo humano, no sólo la zona estética.

Si todo esto es verdad, y también para los representantes de la $R e-$ zeptionsästhetik lo es, resulta un poco curioso que se hable de estética de la recepción precisamente con relación a la literatura. Puesto que ya el término ha sido aceptado en la microlengua de la teoría literaria, podemos seguir usándolo; pero quede claro que mejor sería hablar de teoría de la recepción literaria, sin destacar en ésta el elemento estético.

Pero vengamos por fin a la recepción literaria. En cualquier comunicación tenemos dos polos: el del emisor y el del receptor. La comunicación se suele considerar en la dirección del emisor al receptor. Pero hay que observar que existe otra dirección no menos importante en la comunicación: la que va del receptor al emisor. El receptor, específicamente el receptor literario, no es pasivo. Y cuando hablamos de recepción destacamos el elemento activo del fenómeno. Es probablemente este hecho lo más característico del estudio de la recepción. La ciencia literaria positivista, o al menos las expresiones más áridas de esta ciencia, estudiaba más bien la dirección emisor-receptor, lo que mejor llamaríamos la influencia; olvidaba a menudo la otra dirección. El estu- 
dio de la recepción literaria no la olvida; sin embargo, caería en un error equivalente aunque opuesto si estudiase tan sólo la reacción del receptor: ambas direcciones deben ser tenidas en cuenta; y esta integración corresponde precisamente al espíritu de la estética de la recepción, que pretende, como hemos dicho, ser integrativa y no sustitutiva de otros procedimientos más tradicionales.

A este propósito será oportuno recordar que la afirmación del carácter de negación de la regla como elemento valioso y hasta como el máximo criterio axiológico o valorativo de la llamada creación artística - una afirmación que tiene algún parentesco con el concepto de horizonte de espera afirmado por Jauss-, cae precisamente en la unilateralidad que acabamos de deplorar, aunque se trata de una unilateralidad opuesta a la tradicional. Si la vieja preceptiva encontraba un elemento de valor en la conformidad con la regla y resultaba estéril, esta nueva preceptiva que encuentra un elemento de valor en el rechazo de la regla es igualmente estéril. Por lo demás, un rechazo mecánico de la regla es una manera de cumplir la regla. El receptor activo no acepta ni rechaza en principio las reglas, sino que las utiliza o las modifica o las rechaza según sus exigencias. Son las personas más activas las que están más abiertas a las influencias, decía Goethe, que era un buen ejemplo de ello. Hay casos en que la influencia es explícitamente enunciada. Calderón, por ejemplo, escribía obras que utilizaban obras anteriores, y ponía en evidencia, a veces, esta utilización dando a su obra el mismo título de la obra que le servía de punto de arranque; pero lo hacía precisamente para llamar la atención sobre su manera de utilizar la influencia transformándola: en estos casos la poética de la imitación llega a ser, en realidad, una poética de la originalidad.

Vengamos ahora a tratar específicamente de particulares recepciones literarias, sin la pretensión de llegar a una sistemática taxonomía de la recepción literaria. Hay diversas maneras de recibir una obra literaria. En la Edad Media el receptor de la obra literaria era a menudo un oidor y espectador, así como el emisor era no un escritor sino un juglar. Hay una forma de literatura aun hoy que es institucionalmente parecida: se trata de la literatura dramática. El teatro, no cabe duda, no es sólo literatura: implica varios sistemas semiológicos; pero tampoco cabe duda de que uno, el más importante en general, de estos sistemas es el sistema lingüístico, es decir que el teatro tiene una dimensión literaria. Pues bien: esta dimensión literaria tiene como emisor a un hombre de teatro, más que un escritor, y como receptor a un auditorespectador, más que a un lector. 
Puestas estas premisas, podemos sin embargo afirmar que el objeto principal de una teoría de la recepción literaria es el receptor por excelencia de la literatura, en el mundo contemporáneo: es decir, es el lector. $\mathrm{Y}$ en efecto al lector ha dedicado su particular atención uno de los representantes más conocidos de la estética de la recepción, Wolfgang Iser. Al lector dedicaré aquí mi atención.

La expresión lector puede tener muchas significaciones en la teoría literaria. Hay, aunque parezca paradójico, un lector también en el polo del emisor: el lector puede llegar a ser un personaje del texto; y, con una finura que puede parecer transformarse en sutileza y cavilación, podríamos distinguir muchos tipos de lector en la mente misma del escritor. Pero dejemos esto para otra ocasión y fijémonos en el lector entendido en el sentido corriente del término: el que lee, en este caso, una obra literaria. Dentro de esta categoría se puede, y aun se debe, hacer distinciones, aunque aquellos mismos que se interesan por el lector no suelen hacerlas. Sobre todo, debemos distinguir dos grandes categorías de lectores: los que se limitan a leer y no comunican las impresiones o consideraciones causadas por la lectura: éstos son los lectores que llamaremos lectores finales; y los que no se limitan a leer, sino que comunican los resultados de su lectura a otros. Dentro de esta categoría hay lectores que, al ponerse a leer, no se proponían sino leer, y que sólo en un segundo momento se deciden a comunicar impresiones o consideraciones sobre su lectura. Sin duda, estos lectores se transforman de esta manera en mediadores entre lo que han leído y las personas a las que comunican dichas impresiones y consideraciones; pero se trata de mediadores no intencionales, o al menos no institucionales. Hay sin embargo otras categorias de lectores que se proponen más sistemáticamente elaborar una metalectura y comunicar los resultados de esta metalectura. Son estos mediadores que llamaremos institucionales los que desarrollan un papel importantísimo en la vida literaria, y los que de alguna manera son los objetos privilegiados del estudio de la recepción literaria.

Simplificando, distinguiremos tres subcategorías en esta categoría de lectores mediadores institucionales: los traductores, los libres intérpretes y los críticos.

Los traductores son unos lectores que se enfrentan con una tarea muy complicada: se proponen descodificar los mensajes escritos en una lengua extranjera, para volver a codificarlos en otra lengua, generalmente su lengua natural. No podemos detenernos aquí en el estudio de cómo se realiza la traducción (sobre la traducción se publicó un escrito 
mío en la Revista de Occidente, octubre, 1982, pp. 74-85). Diremos tan sólo que, en consideración del carácter polisémico del mensaje literario, resulta particularmente difícil en el caso de la traducción literaria la tarea del traductor. Éste se encuentra condicionado por múltiples factores externos e internos, lingüísticos y extralingüísticos. Debe aspirar a dar una traducción definitiva, pero ya se sabe que no conseguirá su propósito. Puede tener la tentación de expresar su personalidad en la traducción, pero debe darse cuenta de que lo que el lector exige de él es que desaparezca en lo posible, que sea un mediador transparente y abnegado, fiel al original: exigencias que, como veremos, le acercan de alguna manera al crítico.

Naturalmente, nada prohíbe que alguien no acepte estas reglas; que se dedique no a lo que en general entendemos por traducción, sino a una libre adaptación. A veces puede suceder que la adaptación resulte superior al texto original; durante muchos siglos fue precisamente la adaptación, más que la traducción, lo que se practicó.

Bastante parecido al libre adaptador es el libre intérprete de un texto literario: un lector que reacciona a la lectura sin considerarse supeditado al texto leído; considerando éste como un estímulo para sus propias consideraciones. A los cultivadores de la literatura española se nos ocurre en seguida un ejemplo célebre de parecido tipo de escritura: La vida de Don Quijote y Sancho de Unamuno. En ésta, Unamuno afirma claramente que no pretende aclarar lo que quería decir Cervantes; que de todas formas le parece que Cervantes no comprendía a su protagonista, considerado como una persona de la vida y no como personaje literario. También en este caso debemos decir que nada impide parecida utilización de un texto literario, y que los resultados pueden ser incluso excelentes, como precisamente sucede con la Vida de Unamuno. Se trata de lo que los franceses llaman la trahison créatrice, que puede influir en el desarrollo de la crítica sobre el texto considerado, aunque evidentemente no es crítica.

¿Qué entendemos por crítica? Antes de contestar esta pregunta me parece oportuno aclarar que con esto no pretendemos de manera alguna fundar una deontología de la crítica, así como al precisar qué entendíamos por traducción no pretendíamos esbozar una deontología de la traducción. Se trata tan sólo de aclarar un uso lingüístico: de decir qué entendemos por crítica, al hablar, y qué pedimos, en general, a lo que se nos presenta como crítica. 
En general, pretendemos de la crítica que nos aclare el significado de un texto y nos explique en qué consiste su valor: una doble función pedimos a la crítica: una función hermenéutica y una función axiológica: dos funciones que es oportuno distinguir especulativamente, pero que operativamente en general se entrelazan e incluso se confunden. La función hermenéutica de la crítica nos debe decir cuál es el significado del texto, el significado inmanente en el texto, no el que gratuitamente proyectamos sobre él. La crítica se compromete a ser fiel al texto, a aceptar de él la confirmación o la negación de su interpretación. (Éste ya es un rasgo que la acerca a la traducción, que en este aspecto se puede considerar una forma de crítica muy adherente al texto en sus concretas expresiones).

Naturalmente, hay muchas formas de crítica. La producción críticoliteraria constituye un continuum que nos conviene segmentar para comprenderlo mejor, no tomando, sin embargo, demasiado en serio el resultado de este proceso. Hemos dicho que existe una libre interpretación de un texto, no supeditada a consideraciones de fidelidad al mismo. Hay una crítica adyacente a esta forma de libre interpretación y que sin embargo pretende ser fiel al texto. El mismo Unamuno tiene escritos que interpretan a Cervantes con la pretensión de explicar lo que Cervantes quería decir. Esta pretensión ya califica dichos escritos como crítica. Pero Unamuno tenía un temperamento tan prepotente que es legítimo desconfiar de lo que dice como crítico.

Unamuno, por ejemplo, desprecia las obras llamadas menores de Cervantes y considera el Quijote casi como un milagro, salido de una mente mediocre. Esta tendencia a aislar una obra de su contexto más natural, que son las demás obras del mismo autor, es una tendencia muy difundida, incluso entre los especialistas más documentados. Es difundida porque es cómoda; pero no sólo por esto. Ya hemos superado el exclusivismo de la Textimmanenz; entendemos, o hemos vuelto a entender, que un texto no se comprende sino en sus contextos y en sus circunstancias. (Parece oportuno distinguir entre contexto y circunstancia, reservando el término contexto a los textos escritos contiguos al texto estudiado, y circunstancia a lo que otros pueden llamar contexto histórico extraliterario). Sin embargo, hay mucho que hacer en esta dirección. Los mantenedores de la autonomía del texto tienen una exagerada confianza en la posibilidad de comprenderlo, en la posibilidad de limitarse a la lectura literal. Pero el crítico debe saber que las cosas no son tan sencillas. Las mismas explicaciones que un escritor da a su obra 
no pueden ser tomadas al pie de la letra, como hacen a veces aquellos cervantistas que insisten en la necesidad de limitarse a tomar acta de las declaraciones de Cervantes sobre el significado del Quijote. La realidad es más complicada. Cada época tiene sus condicionamientos y sus represiones. Las afirmaciones que se expresan en ellas hay que leerlas en la clave que la multiplicidad de estas represiones exige. La autointerpretación de un autor puede ser sincera sólo hasta cierto punto: en realidad, ninguno de nosotros es tan complicado, e incluso, sin saberlo, insincero, como cuando habla de sí mismo. Más que las declaraciones explícitas, nos dicen mucho sobre las secretas inspiraciones de un autor sus insinuaciones, sus alusiones, sus sutiles coartadas. Por esta razón el crítico, que quiere llegar a explicar el espíritu íntimo de un texto, debe obviamente tener muy en cuenta cada aspecto de este texto, sus estructuras, su organicidad, y aún más sus incoherencias; pero además debe buscar en los contextos y las circunstancias todo aquello que puede iluminar el texto. Debe reconstruir la situación que ha engendrado el texto y la actividad credora: remontarse del texto, que es un ergon, a la actividad, que es una energeia. La vieja lección del círculo spitzeriano debe estar presente en su mente: saca una hipótesis de explicación del texto, la elabora conceptualmente, pero luego vuelve al texto para oír su sentencia: debe abandonar la hipótesis, o transformarla en afirmación, o modificarla en función del fallo que da el texto. Como el texto es siempre un texto del pasado, más o menos remoto, el crítico es siempre también un historiador, que reconstruye el contexto literario y la circunstancia extra literaria, siempre dejando hablar a los hechos, antes de interpretarlos. La actitud del crítico, en efecto, es, como la del traductor, de abnegación y modestia: el crítico expresa su personalidad, no como el libre intérprete, prestando sus puntos de vista a un texto, lo cual es bastante fácil, sino precisamente esforzándose por llegar a la objetividad. La crítica se propone en efecto, sobre todo, ser objetiva.

Pero ¿qué es, cómo se realiza esta objetividad? ¿Es posible una crítica objetiva, aun en el caso de que el crítico haga el más grande esfuerzo para alcanzarla? Es evidente que en este caso nos proponemos un problema de alcance epistemológico general. ¿Cuál es nuestra posibilidad de llegar al objeto externo a nuestra conciencia? ¿Cómo y hasta qué punto se realiza la adaequatio rei et intellectus? El crítico se coloca necesariamente en un determinado contexto y una determinada circunstancia que en realidad son únicos e irrepetibles: incluso el mismo crítico en un momento anterior o sucesivo representa un punto de vista algo diferente. Iser tiene algunas observciones muy sugestivas sobre la dife- 
rencia profunda entre la primera y las sucesivas lecturas del mismo texto por parte del mismo lector. Otro tanto podemos decir, y con más razón, de aquel específico lector que es el crítico.

Estas consideraciones pueden llevarnos a una tentación de escepticismo. En efecto, no existe la posibilidad de una crítica definitiva. La crítica puede ser objetiva en el sentido que puede y debe ser el producto de un esfuerzo para llegar a una interpretación y a una valoración absoluta del texto; pero no lo es en el sentido de que alcanza lo que el texto es. El texto es indudablemente único e invariable, es un artefacto, como diría Mukarovsky, que está fuera de nosotros, y que no alcanzaremos nunca. Sin embargo, una crítica puede ser objetiva en el sentido perspectivista de la palabra: desde aquel punto de vista, en aquella circunstancia, la crítica no puede ser sino de aquella determinada manera. Por esto podemos decir que hay hasta una oposición entre perspetivismo y escepticismo, que en realidad es una forma negativa de dogmatismo. La crítica puede revelarnos mucho de una obra, vista desde un punto de vista. Lo importante es la autenticidad y la madurez de este punto de vista.

A menudo los críticos ponen, al comienzo de su estudio sobre un texto, o más en general un tema literario, una historia de la crítica. Estas reconstrucciones suelen perfilarse de una de las maneras siguientes: por un lado, la historia de la crítica delineada por el nuevo crítico pretende demostrar que todos los críticos hasta el que escribe se han equivocado, y que ahora llega por fin el que da la clave definitiva del texto o del tema; por el otro, la historia de la crítica se concibe como un desarrollo teleológico unívoco, es decir, finalizado a la conclusión definitiva, que es naturalmente la interpretación que el crítico se propone exponer. Ambas concepciones suponen que existe una interpretación definitiva, ne varietur, de un texto o de un tema. En realidad, una interpretación así no existe. Como la obra es siempre una obra abierta, aun en el caso de que el mismo autor haya dado de ella una interpretación que pretende ser definitiva, así la crítica es siempre abierta.

Esto no quiere decir que la actividad crítica es un volver a empezar cada vez desde la nada. Hay críticas objetivas, que han realizado concreciones muy valiosas del texto, que lo han iluminado y hasta enriquecido.

La concreción crítica de un texto es siempre, más o menos intencionalmente, una actualización del mismo. La actualización es un ejer- 
cicio peligroso, quiero decir particularmente peligroso (nada, en efecto, existe que no tenga sus peligros). Puede llevar a una interpretación tendenciosa e instrumental, por ejemplo al servicio de un poder político. Además, no existe una actualización canónica en un determinado momento. Una interpretación teleológica de la historia puede hacer creer que un momento histórico tiene un determinado sentido unívoco. Pero no existe una coherencia histórica de esta naturaleza. La historia es un enredo de historias; hay en ella continuidades y discontinuidades, y hasta las continuidades no se desarrollan de manera uniforme, sino que tienen algo sorprendente, aventurado y hasta contradictorio. Durante un momento histórico hay muchas continuidades históricas en momentos diferentes de desarrollo; y estas continuidades se influyen de una manera inextricablemente compleja.

Algo parecido encontramos en el microcosmos del desarrollo de una crítica referente a un determinado tema. Las críticas son diferentes necesariamente, y por lo tanto legítimamente diferentes. Precisamente por esto, aun cuando se presentan como contradictorias, en realidad resultan complementarias. En una concepción tan pluralista puede uno estar tentado de creer que todas las críticas son equivalentes. No es así: algunas son estimulantes, revelan aspectos nuevos; otras son estériles, repetitivas, superficiales, borrosas.

A propósito de la novedad de la crítica, hay que decir que determinadas interpretaciones de un texto podrían resultar nuevas y sorprendentes hasta para el mismo autor del texto, y sin embargo ser perfectamente justificadas por el texto mismo. Como la posteridad puede entender de una manera diferente, y sin embargo legítima y hasta más profunda, un acontecimiento entendido de otra manera por los contemporáneos y por los mismos que lo causaron, porque el significado histórico de un hecho resulta de su perspectiva histórica, que por definición los contemporáneos no pueden tener, lo mismo acontece que la crítica puede dar una interpretación actualizante y sin embargo legítima, objetiva, de un texto: revelar en el texto significados que quedaban escondidos a los contemporáneos y hasta al mismo autor, y que sin embargo están inmanentes en él. La crítica puede de esta forma enriquecer el texto sin forzarlo. Los grandes clásicos de la literatura tienen para nosotros un significado que no podían tener para los contemporáneos, y que sin embargo está inmanente en ellos. Puede haber en este significado algo de trahison créatrice, pero en cierto sentido algo de ésta es también inmanente en la obra. Los siglos con sus interpretaciones han sedimenta- 
do significados derivados de los grandes textos; los críticos, como artífices additi artifici, los han enriquecido, pero en coherencia con su naturaleza. La recepción literaria es a su vez una creación literaria que no se cansa nunca de enriquecer el significado de determinados textos. De determinados, claro está, no de todos: se trata de los textos en que se expresa de la manera más holística, más total, la humanidad, a través del medio expresivo más característico, más vario, más flexible de la humanidad, la lengua ${ }^{2}$.

2 Algunas lecturas hechas después de la redacción de las páginas anteriores confirman el mayor interés de la reflexión literaria para el lector y la lectura, es decir para la forma actualmente dominante de recepción literaria. Este mayor interés se acompaña a menudo con actitudes críticas frente al tipo de estructuralismo que prevalecía especialmente en Francia, en los años sesenta. Por ejemplo, Robert Scholes, autor de un conocido libro sobre Structuralism in literature, abandona la concepción de la autorreferencialidad de la literatura, afirmada por Jakobson de acuerdo con los New Critics, dándose cuenta de que, abandonándola, se aleja «de una poderosa tradición en los estudios semióticos que va de Saussure a Barthes y a Eco) (Towards a semiotics of Literature, en el tomo What is Literature?, Indiana University Press, 1978).

En realidad, el mismo Eco afirma ahora que ya en 1962 hacía, sin saberlo, «pragmática del texto», estudiando la actividad cooperativa del destinatario (Introduzione a Lector in fabula, Milán, Bompiani, 1979). En 1978 se tradujeron al francés algunos escritos de Hans Robert Jauss, ya conocidos en otras partes (por ejemplo la traducción italiana de Literaturgeschichte als Provokation der Literaturwissenchaft, a cargo de Alberto Varvaro, se remonta a 1970). Pero parece que la afirmación definitiva fuera de Alemania de la llamada Estética de la recepción se puede colocar en los años 1979 y 1980. En 1979 tuvo lugar en Innsbruck el IX congreso de la Asociación internacional de la literatura comparada, una sección del cual se dedicó a la recepción literaria. Sobre el segundo tomo de los Proceedings de Innsbruck, que recoge las ponencias presentadas en dicha sección, publiqué una reseña en Canadian Review of Comparative literature, March, 1983, 86-96, por lo cual no es necesario que me ocupe aquí de él. En 1980 la Revue des sciences humaines dedicó un número a $L$ 'effect de lecture, al cual aludo en un escrito titulado Lettori e letture en los Annali dell'Istituto Universitario Orientale de Nápoles, Sezione Romanza, 1983, 125-137. Aquí quisiera detenerme sobre otro número especial, el dedicado en septiembre de 1979 por la revista francesa Poétique a Théorie de la réception en Allemagne. El número ha sido compuesto por Lucien Dällenbach, que puso a su frente un par de páginas sintomáticas, en las que se afirma que la investigación francesa ya está dominada por líneas que convergen en el reconocimiento del destinatario y de la recepción: el interés por el tema más allá de sus marcas lingüísticas, la renovada atención por la teoría de los géneros y el juego intertextual, la vuelta a las fuerzas de la historia, la curiosidad por la filosofía analítica anglosajona, la vuelta a los actos concretos de lenguaje, el cambio de dirección de la poética, que reniega de su fase jakobsoniana para convertirse sin retorno a la pragmática. Mientras la investigación francesa de los años sesenta había quedado anclada en el estructuralismo prepragmático (es decir, que ignoraba la relación entre acto lingüístico y situación vital), la alemana, concluye Dällenbach, elaboraba ya la estética de la recepción. 
En el número de Poétique se recogen escritos, ya publicados en alemán, de Jauss, Iser, Weinrich, y otros de autores menos conocidos; aquí prefiero destacar uno sólo, el de Rainer Warning, Pour une pragmatique du discours fictionnel. Warning había publicado en Munich 1975 el conocido reader Rezeptionsästhetik. En el citado congreso de Innsbruck había introducido, dentro de dicha sección, el grupo de estudio dedicado a las relaciones entre teoría de la recepción y semiótica. Había afirmado que el estudio de la recepción en Alemania se había colocado, ya en los años sesenta, en postura crítica frente a la ola del primer estucturalismo que dominaba en Francia. (Análoga era la actitud, en América, de Michael Riffaterre, afirmador de una estilística del contexto relacionada con el lector). En su primera fase, el estructuralismo se vinculaba a la contraposición binaria saussuriana de langue y parole, descuidando la parole en favor de la langue, es decir, del sistema de signos lingüísticos. Pero tal sistema se realiza en la comunicación a propósito de objetos exteriores a la lengua. Warning se vincula, al contrario, a Charles Morris, que no limita la semiótica lingüística a los códigos (sintaxis y semántica), sino que se ocupa de la utilización de los signos (en este caso de los signos lingüísticos): hay también una pragmasemiótica, o, sin más, pragmática. La Rezeptiosästhetik ha anticipado la fase pragmática del estructuralismo, colocándose, desde luego, no en contraposición a la estética de la producción, sino como complemento de ella.

Estos principios Warning los aplica, en el escrito de Poétique, a la pragmatique du discours fictionnel. Se ha distinguido un discurso pragmático, dirigido a conseguir efectos fuera de la lengua, y un discurso fictionnel, es decir referente a una narrativa de invención. Sin duda, en un narrativa de invención no hay una relación inmediata con una situación exterior. Don Quijote pensaba que lo que leía de los caballeros andantes era la realidad; pero se equivocaba. Sin embargo, existe una relación aún de la narrativa de invención con la realidad exterior. La narración de invención supone una situación histórica, tiene un carácter contractual. El discurso de invención, así como el discurso no de invención, se integra en una práctica social transcendente. La ironía de Flaubert no es autorreferente, sino que se refiere «a aquel conjunto de normas, a aquella situación histórica que comprende la situación interna de enunciación y la situación externa de recepción».

Las consideraciones de Warning me parecen tan razonables que la necesidad de afirmarlas puede sorprender a los que no estén en antecedentes. Ya sabemos que hay la posibilidad de una pragmaticidad grosera del texto literario. En realidad, lo que Warning llama estructuralismo prepragmático es una continuación del art pour l'art del siglo pasado. La autonomía del arte fue afirmada para defender el arte de las instrumentaciones contaminantes que lo acechan desde múltiples direcciones y desde siempre. Pero no existe una pura autorreferencialidad del texto. La pretendida autorreferencialidad es sólo una forma más mediada y alusiva de heterorreferencialidad. Una pragmaticidad explícita de un texto no significa, por otro lado, una automática inferioridad literaria del mismo. Una oración de Demóstenes o de Cicerón es una obra pragmática, pero esto no la descalifica automáticamente como obra literaria. Una interpretación, pongamos, de una novela de ambiente hispanoamericano como documento social puede ser ingenua; sin embargo, el propósito del autor era probablemente también el de insinuar una determinada imagen de la sociedad aludida. Aunque no fuera ésta la intención, éste es el efecto pragmático, que influye en la recepción de la novela, y en realidad es inseparable de su valoración literaria por parte del receptor. 